Faculty of Education

Te Kura Toi Tangata

Waikato Journal of Education

Te Hautaka Mātauranga o Waikato

Volume 16, Issue 2: 2011 


\section{WAIKATO JOURNAL OF EDUCATION TE HAUTAKA MĀTAURANGA O WAIKATO}

\section{Editors:}

Jane Strachan

Noeline Wright

\author{
Editorial Board: \\ Beverley Bell \\ Bronwen Cowie \\ Deborah Fraser \\ Margie Hohepa \\ Sally Peters \\ Noeline Wright
}

\author{
Margaret Carr \\ Rosemary DeLuca \\ Richard Hill \\ Judy Moreland \\ Clive Pope
}

Waikato Journal of Education is a refereed journal, published annually, based in the Faculty of Education, The University of Waikato, Hamilton, New Zealand. It publishes articles in the broad field of education. For further information visit the WJE website http://edlinked.soe.waikato.ac.nz/research/journal/index.php?id=8

Correspondence and articles for review should be addressed to: Research Manager, Wilf Malcolm Institute of Educational Research, Faculty of Education, The University of Waikato, Private Bag 3105, Hamilton, 3240, New Zealand. Email: wmier@waikato.ac.nz

Business correspondence: Orders, subscription payments and other enquiries should be sent to the Administrator, Waikato Journal of Education, Wilf Malcolm Institute of Educational Research, Faculty of Education, The University of Waikato, Private Bag 3105, Hamilton, 3240, New Zealand, Email: wmier@waikato.ac.nz

Subscriptions: Within NZ \$40; Overseas NZ \$50

Copyright: (C) Faculty of Education, The University of Waikato

Publisher: $\quad$ Faculty of Education, The University of Waikato

Cover design: Donn Ratana

Printed by: Waikato Print

\section{Call for papers}

The Waikato Journal of Education provides an avenue of publication for quality articles on education. This peer-reviewed journal welcomes a range of topics including interdisciplinary, philosophical and applied research approaches.

Submissions are now invited for consideration for publication in the November 2012 issue. Please submit an electronic copy and a separate page with author/s contact details by 30 April 2012 to WMIER Research Manager, Carolyn Jones (cjjones@waikato.ac.nz), Faculty of Education, University of Waikato, Private Bag 3105, Hamilton 3240, New Zealand. 


\section{Waikato Journal of Education}

\section{Te Hautaka Mātauranga o Waikato}

Volume 16, Issue 2: 2011

\section{Special Edition: A teacher education partnership between the Solomon Islands and New Zealand}

Editorial

The Solomon Islands School of Education Partnership: Aspirations, context and design in educational change

Clive McGee and Patricia Rodie

Partnership experiences in developing the Preparation for Tertiary Learning course in the Teachers in Training programme

Roselyn Maneipuri, Immaculate Runialo and Noeline Wright

Making sense of health education in the Solomon Islands

Kirsten Petrie and Mark Tehe

The Solomon Islands mathematics: Pedagogy in transition?

Nigel Calder, John Beuka and Calvin Ngatulu

Taking ownership: The story of a successful partnership for change in a Pacific Island science teacher education setting

Richard Edwards, Solomon Pita and James Porakari

Funds of knowledge: Developing a Diploma in Teaching in Early Childhood Education in the Solomon Islands

Janette Kelly, Joanna Daiwo and Viola Malasa

Weaving a "Hybrid Mat": Samoa meets the Solomons

Barbara Whyte

Sustaining organisational change: Teacher education in the Solomon Islands Jane Strachan, Susanne Maezama and Janine Simi

Exploring factors that influence school planning in community high schools in the Solomon Islands: Principals' perspectives

Samuel Aruhu and David Giles

Experiences of being a leader in Choiseul Province: Opening principals' and deputy principals' contexts of leadership

John Sisiolo and David Giles

Book review 
Waikato Journal of Education

Te Hautaka Mātauranga o Waikato

Volume 16 Issue 2: 2011

\title{
Exploring factors that influence school planning in community high schools in the Solomon Islands: Principals' perspectives
}

\author{
Samuel Aruhu \\ Principal \\ Pamua National Secondary School \\ Solomon Islands \\ David Giles \\ Flinders University \\ Australia
}

\begin{abstract}
This article reports on an investigation of the factors that influence school planning in community high schools in the Solomon Islands. In particular, it examines principals, experiences of having worked with school plans. While the international literature focuses on school planning and the planning process, much of this literature relates to Western contexts, which are sometimes irrelevant to the context of a developing nation such as the Solomon Islands. Thus contextual specificity is an important underlying factor in the study. While school planning is critical for schools, this research showed that most principals in community high schools in the Solomon Islands do not have the confidence to formulate, implement, and successfully evaluate a school plan.

As qualitative research, this research gathered stories from community high school principals on Makira Island through semi-structured interviews. These interviews were analysed on a case-by-case basis and used a thematic analysis approach.

Key findings of this research, regarding school planning, include the urgency of providing professional development and ongoing support for community high school principals, the role and priority of interpersonal and school-community relationships, the critical importance of school planning as a process, and the notion of seeing a school plan as a working, living document that supports the activity and development of a school.
\end{abstract}

Implications from this research include the need for current and future school principals to undergo professional development that is geared towards improving

Faculty of Education, University of Waikato, Hamilton, New Zealand

ISSN: $1173-6135$

(pp. 107-121) 
understanding and skills in school planning. A thorough understanding of the essential elements of the school planning process, alongside ongoing support, will greatly enhance current and future community high school principals' capacity to improve planning in their schools.

\section{Keywords}

School development, strategic planning, leadership, school culture.

\section{Introduction}

Schools have been engaged in planning within the secondary school context of the Solomon Islands as early as the 1900 s when formal education was first introduced to the island state by missionaries (Ramoni, 2000). However, school planning during this time was not compulsory; it was left to the principal's discretion. This trend changed from the late 1980s with the advent of the neo-liberal agenda that promoted accountability for schools (Davies \& Ellison, 1997). It was during this period that schools were required to produce school plans (Davies \& Ellison, 1997). In most national and community high schools in the Solomon Islands, school planning was seen to be one of the major roles of the school principal and deputy. The rest of the staff, students, parents and other stakeholders of the school did not play an active part in this.

The rapid establishment of community high schools (CHS) throughout the Solomon Islands since 1995 has meant that many of these schools were staffed by inadequately trained teachers and inexperienced principals (Solomon Islands Ministry of Education, 2004). This situation led to a lack of proper planning in the community high schools, which has resulted in lessening standards in schools and criticisms from parents and senior members of the community about the deteriorating state of schools (Malasa, 2007).

Although no research has been conducted on how schools plan in the Solomon Islands secondary school context to substantiate the above claims, school planning is considered to be critical to a school's success (Hargreaves \& Hopkins, 1991; MacGilchrist, Mortimore, Savage, \& Beresford, 1997; Stoll \& Fink, 1996). As such, school planning needs to be investigated to fully realise how it contributes to a school's development. This article reports on research that explored factors influencing school planning from principals' perspectives (Aruhu, 2010).

\section{School planning}

Lipham and Hoeh (1974) highlight the process of school planning "as those activities related to defining and clarifying goals, purposes and objectives, investigating conditions and operations related to purposes and objectives considering possible alternatives and recommending changes to be made" (p. 81). Until the late 1980s, there was no formal requirement for schools to produce school plans. There is now a general trend in education in which schools are expected to develop their own school plans (Caldwell \& Spinks, 1988, 1992; Hodgkinson, 1991; Stoll \& Fink, 1996). Recent educational reforms have promoted the need for transparency and accountability in schools. These reforms required principals to be actively involved in school planning to ensure that stakeholders benefit from the services the school delivered. It was seen as 
critically important that planning be undertaken by those vested with responsibilities for leading in schools and other educational institutions (Helm, 2005). Moreover, planning was seen to link to bringing about intended outcomes to increase the effectiveness and efficiency of schools (Caldwell \& Spinks, 1988, 1992; Hodgkinson, 1991; Stoll \& Fink, 1996; Waddel, Cummings, \& Worley, 2000). This has led to the notion that effective school planning is a key to sustainable educational reforms that builds capacity and autonomy and focus resources on staff and system success (Glover \& Levacic, 2005; Helm, 2005; Knoff, 2005).

Studies have yet to explore school planning in developing countries of the South Pacific, especially in Melanesian countries like the Solomon Islands. Most of the school planning research has been carried out in developed countries such as the United States, the United Kingdom, Australia, New Zealand, and some European countries. Dimmock and Walker (2002) noted that most of the findings are based on Eurocentric or AngloAmerican theories, values and beliefs. They argue that "although cross-fertilization of ideas and approaches is generally beneficial, there are dangers in failing to recognise that theory, practice and imported expertise may not readily apply across national and cultural boundaries" (Dimmock \& Walker, 2002, p. 167). There are also questions about whether principals and schools in developing countries, such as the Solomon Islands, would have the capacity and resources to be effectively engaged in the school planning practices as identified in the literature. As Davies (1994) notes, the economy and cultural constraints of developing countries can influence how principals approach their school planning roles and tasks.

This article describes one Solomon Islands' principal's efforts to learn more about school planning.

\section{Sam's interest in school planning}

Sam's interest in school planning began when he was first appointed as a deputy school principal in the Solomon Islands in 1997. Halfway through the year the school principal resigned and Sam was temporarily appointed to take charge of the school through to the end of the year. This appointment alerted him to the need for some documented evidence of the school's plans and goals. His interest in school planning was further enhanced through postgraduate study in New Zealand. Reflecting on his study, Sam realised that a number of school principals in the Solomon Islands did not appear to have the capacity to formulate and implement an effective school plan.

Researching in this area, Sam hoped that some factors that influence effective school planning from the principal's perspective within community high schools in the Solomon Islands might be identified. ${ }^{i}$ Through the provision of resources and labour, the local community typically constructs the community high school. Most often the community has a sense of ownership of the school as a consequence of their involvement in establishing it. Thus educational resources are scarce and need to be used in accordance with school plans to ensure that the aims and objectives of the school are met.

David is one of Sam's critical friends who supported this research inquiry. David's particular interest in this inquiry was the hermeneutic interpretations of the participant's experiences towards emergent themes, given his research interests in hermeneutic 
phenomenology (Giles, 2008). In this way, we sought to complement each other's knowledges of context and method.

\section{Methodology}

In attempting to understand the concerns of school principals with regards to school plans, we made a decision to investigate principals' experiences of having worked with school plans. Designed as interpretive research, the specific focus of this research is captured in the following question:

What factors influence school planning in community high schools in the Solomon Islands from the principal's perspectives and experiences of having worked with school plans?

This research project adopted a case study research approach to gain first-hand indepth information on the social reality under inquiry (Bouma, 1996). Semi-structured interviews were used as an in-depth conversation with participants regarding their experiences and perceptions. Participants were involved in a single, 45-60 minute, faceto-face, semi-structured interview. The participants and the community high schools within which the interviews were conducted are identified with pseudonyms.

\section{Participants}

Six community high school principals on Makira Island province in the Solomon Islands were selected as the sample for this research project. The six participants were all men and came from different parts of the province, one of the nine that make up the Solomon Islands. Even though the participants came from the same province, they have diverse cultures, languages and customs. The first participant, whom we call Sailosi, comes from the eastern part of Makira province, McGregary and Charles come from the Central region, while Roger, Ratu and Fox come from the western part of the island province. Four of the participants have a Diploma in Teaching (secondary) qualification, one has a Bachelor of Education and one has a certificate in tropical agriculture. On top of their daily responsibilities as school principals, the participants assist in classroom teaching. The participants have been principals from one to twenty years. All except one started their teaching career as a secondary teacher. The other had been an agriculture field officer before joining the teaching profession. The participants' teaching experience ranged from four to thirty-nine years.

\section{Ethics}

As a citizen of the Solomon Islands, Sam was very aware of the cultural backgrounds of the participants. This includes the accepted cultural protocols within the school communities. The University of Waikato's ethics committee gave ethical approval for this research.

\section{Data analysis}

A thematic data analysis approach was adopted as this is a commonly used strategy for analysing and reporting qualitative data (Mutch, 2005). This thematic analysis is a qualitative strategy that takes its categories from the data. It focuses on identifiable 
emergent themes and patterns (Aronson, 1994; Giles, 2008). For more detail on this process see Giles (2008).

\section{Findings and discussion}

Research data were analysed for distinctive features of each case and secondly, a process of thematic analysis was used to elicit emergent themes across the cases. This paper reports briefly on emergent themes across the cases.

\section{Theme 1: School plans are critically important}

The participants recognised the importance of school plans and the planning process as a major contributing factor to a school's success. As such, the involvement, participation and contribution of all the stakeholders is of paramount importance to ensure that the school plan is well developed and achieves the aims and goals of the school. The Daula CHS principal elaborates:

... school planning contributes to ... a school's success. If you do not plan your school properly, it is very likely that your school is heading towards failure. ... school principals take for granted that a school can run effectively with little or no planning ... My experience is that you need to plan to ensure that you achieve the goals and targets of the school.

By co-ordinating aspects of planning that are otherwise separate, the school acquires a sense of direction and is able to control and manage more easily the tasks of development and change (Hargreaves \& Hopkins, 1991; Hargreaves, Hopkins, Leask, Connolly, \& Robinson, 1989; Hopkins, Ainscow, \& West, 1994; Hopkins, 2001).

Findings indicate that participants are aware of the different needs of the school that need to be taken into consideration during planning. One way to ensure that these demands and expectations are fulfilled is to develop practical school plans. As some principals stated:

Planning involves ... the whole aspect of the school ... school plans govern all the activities we plan to do.... (Daula CHS principal)

... the school infrastructure ... is still developing. We need to come up with realistic plans to address this ... we have to plan. (South West CHS principal)

Davies and Anderson (1992) suggest it is essential that an assessment of the current position of the school is undertaken first. This determines where the organisation is now and what its curricula, staffing, material, infrastructure and priorities are. Hopkins (2001) states that planning is a means by which schools organise what they are already doing and what they need to do in a more purposeful and coherent way.

It is important that time is devoted to creatively thinking about, and focusing on, the future to ensure a proactive stance. Although it is not possible to know precisely what the future will bring, current trends and indicators can help to provide useful insights in developing a credible perspective. By examining trends and building scenarios of possible outcomes, leaders can develop a futures perspective of the school. In this way, school planning involves a journey of thinking in which those involved in the planning 
process extrapolate patterns from the past and project these into the future (Davies \& Ellison, 1997, 1999). This approach to planning is especially helpful when working in a newly established school. The Frigate Bird CHS principal comments:

Working in a newly established ... school ... needs ... time to think and plan for what is best for the school.... This gives you the urge to keep on working hard even when you come across difficulties.

\section{Theme 2: School plans are working, living documents}

Findings showed that participants think of school plans as working, living documents that support the activity and development of a school. As the Daula CHS principal comments:

... think of a school plan as a working tool which is derived from ... people who have an interest, participate and are involved in the activities of the school ... as a living document which serves as a reference point for all that you do in the school ... I believe that compiling a school plan only to satisfy school requirements without actually using it is a waste of time, effort and money.

As a working document, a change plan guides the strategic direction of a school. As such, it requires the participation and involvement of all those who have a vested interest in the school. Davies and Ellison (1997) state that "in too many cases, the document becomes so detailed and unwieldy that it cannot be used as a working document. A useful phrase to remember is "the thicker the plan the less it affects classroom practice"' (p. 91). Once a school plan has been developed, it should be used as a document to monitor the progress of planned activities in a school, and as a framework for modifications, should circumstances change (Davies \& Ellison, 1997).

From the principals' experiences, planning is one way of demonstrating accountability. Those schools that do not engage in planning appear to be more likely to misuse school resources or use them in ways that do not bring about maximum benefits to the school.

\section{Theme 3: Relationships are critical to the process of school planning}

Relationships are vitally important in the development and implementation of successful school plans. As such, relationships need to be established and well maintained amongst all the stakeholders. Internally, the principal needs to establish and maintain positive relationships with members of staff, students, and families. Externally, the school must build and maintain positive relationships with the controlling authorities like the Ministry of Education and Human Resource Development and the local community. This position was shared by the St Vincent CHS principal:

I strongly believe that the underlying factor for implementing a successful school plan is establishing and maintaining a strong positive relationship with all the stakeholders of the school. Without this positive relationship students cannot perform to the best of their abilities, communities would not support and actively participate in school 
programmes, and therefore the plans of the school cannot be successfully implemented.

Day, Harris, Hadfield, Tolley and Beresford (2000) suggest that the most important aspect of leadership is working successfully with people; establishing relationships in which their leadership can be expressed. Being a head is not a "desk job" (p. 45), though it involves organisational and administrative skills. It is about having positive relationships with those with whom you work. Gunter (2001) stressed the importance of developing positive and productive relationships as this enables positive change in schools. Without positive relationships, people will not be motivated to be involved in the formation and implementation of the school plans.

\section{Theme 4: The school principal}

School principals need to establish and maintain a positive working relationship with those they interact with at work and during other times where school activities are occurring. These relationships are essential for the effective implementation of school plans. The St Vincent CHS principal comments:

I believe so much in building a strong school-community relationship and in maintaining it. Not only between the school and the community but within the school setting itself; this relationship should also be shared amongst the members of the staff and the students. If this relationship is well established and maintained it should strengthen the implementation of the school plans, so that they can become more effective.

Knoff (2005) states that relationships determine all levels of improvement and success in a school. Principals therefore, need to foster collaborative relationships among all the individuals actually working on a school plan. In his study of relationships in schools in the USA, Donaldson (2006) observed that most schools are functioning as if relationships among staff and between staff and parents are unimportant, unmanageable, or simply unmentionable and suggests that school leaders, working in school cultures so inhospitable to valuing relationships, face a major challenge to make these relationships a priority. All the participants agreed that unless there is a positive relationship between the principal and the school, nothing much can be achieved for the school. The Star Beach CHS principal states:

I believe that teachers must work together as a team in order to improve the school and deliver the best possible education to the children.

The South West CHS principal adds:

You ... need ... a sound working relationship between your staff and students. These two groups of people ... play an important role in implementing a successful school plan.

By involving staff and students in the school planning process, there is the likelihood that shared understandings and commitments to the school's plans can emerge. Building relationships then is not just a matter of managing people but of providing the leadership necessary to harness the valuable resources in the form of the people (Duignan, 2006). The participants agreed, as the Daula CHS principal observes: 
All the ... stakeholders must have a sense that they own the school plan. These positive working relationships ... must grow mutually so that the school plan can be successfully achieved.

If the principal encourages the staff and students to become involved and participate in the school planning process, they are more likely to have a sense of ownership of the school plan, thereby developing a commitment to its successful implementation.

\section{Theme 5: The school community}

The findings of this research indicate that participants value the relationships that have been formed between the school and their local communities. This may be because schools are dependent on local communities for support towards the implementation of school plans, especially with regard to capital projects. Local communities assist schools by providing the raw materials for school building projects. The principal of $\mathrm{St}$ Vincent notes that:

St Vincent relies very much on the relationship it has established with the community, particularly with regards to resources which the school rely on from the community. The school also relies very much on the support and participation of the local community to successfully implement its programmes.

Participants also spoke of experiences when relationships were difficult to maintain, especially during the implementation stage of a school plan. The principal of South West CHS elaborates:

... maintaining a positive school relationship is easier said than done. You are working with people with different ideas, opinions and perspectives about how things should be done in the school. It is quite difficult to ensure that all the stakeholders' expectations are satisfied with regards to school planning. Sometimes relationships between the different parties involved in school planning can become hostile and you have to ensure that these differences are settled.

The participants acknowledged that, although school-community relationships are critical and should be well maintained at all times, sometimes these relationships can be strained. It is critical that school leadership take the first move to restore these relationships. The principal of Star Beach CHS recalls:

Realising that the school was in a total mess, and that community support and participation was low, the first initiative that I took was to go around the school ... communities and gain an awareness in an attempt to restore community support, participation and confidence in the new school leadership.... I emphasised to them that unless the school and the communities work together, very little can be achieved.

\section{Theme 6: Leadership styles}

Participants displayed different leadership styles while working with their school plans. The style of leadership a principal demonstrates can have a significant impact on the outcome of a school plan. These research findings identified two main leadership styles displayed by participants while working with their school plans. 


\section{a) Hierarchical (top-down)}

While participants acknowledged the importance of shared or distributed leadership, there were times when they had to fall back on a hierarchical style of leadership. As the person responsible for the overall management of the school, the principal had to ensure that the work was done. This appears to be the case with community high principals in this study. The Daula CHS principal comments:

I put down due dates that I expected my staff to complete the tasks that have been delegated to them. Once I informed them about what is required to be done and the date that I expected them to complete the given tasks, the staff all worked together to accomplish the task before the due dates. However, if you delegate tasks without giving them due dates, it is most likely that task will never be completed.

\section{b) Shared leadership}

Findings showed that while participants sometimes fell back on a hierarchical leadership style, there was evidence of shared leadership being practised at the school level. Principals encouraged their staff to become involved in the planning process by assigning responsibilities and by encouraging contributions and ideas towards the development of the school plan. The principal of Daula CHS explained:

... the staff are assigned to various areas of responsibilities within the school ... we draw a lot of ideas, opinions and perspectives from a whole lot of different people within and outside the school. So when it comes to planning I often look at the potentials or experiences of these people....

Current discourses on the preferred styles of educational leadership generally advocate a shared leadership model. There is a growing belief that leadership should, and must be, shared throughout an organisation. The Daula CHS principal comments: "All the school groups formulate their own plans for the activities that they will do during the course of the year."

While some people may view this as merely a delegation of responsibilities to members of the staff, we would argue that this is an example of shared leadership, in which those who are involved in planning are entrusted to take a leading role in the formulation of a school plan. Noonan (2003) states that the level of participation needs to be appropriate to the importance of the decision and the member's contribution to the decision-making process. "The greater the impact of the decision on individuals and the organisation the higher the level of member participation is required" (p. 39).

\section{Theme 7: The planning process}

Findings suggested that participants were not confident working with school plans. This is not surprising as most community high school principals are promoted directly from teaching positions with little deliberate professional preparation for leadership roles. Amongst the participants, only two of the community high school principals served as deputy school principals before being appointed principal. A lack of understanding and 
inexperience working with school plans may have contributed to inadequate planning evident in some schools. This view is shared by the principal of Frigate Bird CHS:

... as a newly appointed principal, I am really struggling to make a plan for my school. I was never taught how to make a school plan ... I have a lot of challenges in terms of school planning....

The lack of initial principal preparation may have contributed to this lack of understanding about school planning - a view supported by Akao (2008) and Malasa (2007). However, as Malasa (2007) states, the Solomon Islands Ministry of Education and Human Resources Development is fully aware of this concern and has proposed initiatives aimed at addressing the planning needs of schools.

\section{Theme 8: Audit}

Findings indicated that participants recognised the importance of auditing the current position of the school as the basis for effective school planning. The Star Beach CHS principal stated:

You cannot do anything in the school unless you identify what needs to be done. You have to look at the present position of the school and ask yourself some questions... You cannot do real planning unless you have identified what needs to be done.

The St Vincent's principal shared this concern, saying that:

Schools have their own unique contexts and one thing that is proved successful in one school does not necessarily become successful in another school. As a school principal you have to take account of the particular school context you're working under.

Davies and Ellison (1997) suggest that a thorough overview is required during the auditing process as false assumptions at this stage can lead to wrong decisions later on. The principal of Daula CHS commented:

Before we can plan ... we need to know how much school finances we have available to facilitate the implementation of our plans.... The Ministry of Education ... supply us with this information as well as about terms and holidays, school material resources they will supply and other relevant information needed to assist us with our planning. So based on this information the school is able to plan for the activities it will engage in....

\section{Theme 9: Plan construction}

Findings show that during the construction phase of the plan, participants were aware that priorities selected for implementation should be achievable. Apart from selecting achievable priorities, it is also important that only a few priorities are selected. Stoll and Fink (1996) noted that one of the most challenging features of school planning is the ability to keep the plan to a realistic and manageable size. The Daula CHS principal comments:

Another area which I think is important and can influence school planning is setting achievable goals. It is not good to plan for things that 
are impossible to achieve. Your staff will become frustrated if they do not experience success. You need to set achievable goals in your school plan to motivate your staff....

The choice of priorities, according to Hargreaves and Hopkins (1991), should be based on manageability.

\section{Theme 10: Implementation}

The successful implementation of a school plan depends on the active participation and involvement of all stakeholders. The Daula CHS principal commented:

I believe that the success of [school plans depends on] how much time, commitment and dedication ... stakeholders put into ... implementing the school plan.

Through regular communication, goals and tasks are clarified. The St Vincent CHS principal stated:

There should be a two-way communication during the implementation in which those who are responsible for certain areas of the school plan communicate to the principal's office and the principal's office should communicate with those who are responsible for the implementation process.

In addition, the Daula CHS principal elaborated:

Even if a school comes up with an excellent school plan it can end up achieving nothing if those that are delegated with responsibilities are not carrying out their tasks. Sometimes community high school principals do not take precautions or measures to ensure that those delegated with responsibilities carry out their tasks satisfactorily.

\section{Theme 11: Evaluation}

The evaluation of a school plan is integral to the whole planning process. It would appear that most schools were not carrying out this stage effectively. Findings showed that participants lacked understanding as to how they might conduct an effective evaluation of their school plans. School principals need professional development in this area. The Star Beach CHS principal commented:

The monitoring process in my opinion is an instrumental part of planning because it checks on the strengths and weaknesses of the school plan, so that weak areas can be attended to in time rather than waiting for the end of the year.

\section{Theme 12: The priority of professional development and ongoing support}

One of the major concerns raised by the participants was the inadequate preparation for taking up a leadership role as a school principal. Most claimed that they were appointed to principal posts without an induction or initial leadership education. It would appear that most CHS principals are promoted directly from a teaching role into leadership positions. The lack of initial principal preparation has negative consequences for schools in terms of planning. The Daula CHS principal commented: 
... a lot of community high school principals are ignorant of their roles ... [the] lack of understanding [has] negative implications for their schools and communities.... Having this knowledge and understanding will greatly improve the work of principals in our schools ... a lot of principals currently serving in our schools are just classroom teachers without any qualification to lead in our school.

The participants frequently suggested that most principals serving in community high schools in the Solomon Islands were not confident with school plans. While the principals interviewed showed evidence of increasing confidence in school planning resulting from their experience in schools, participants suggested that there were a significant number of principals who had been recently promoted from classroom teachers to a managerial role without experience or induction on school planning. School plans are the basis of funding from the authorities. As a consequence, these are important documents for the resourcing of schools. Engaging in ongoing professional development and organising ongoing support may assist these principals to gain a better understanding of the nature and process of school planning as this also builds their leadership capacities. The Star Beach CHS principal stated:

I believe that current school principals really need this training. There are lots of community high school principals ... who do not know what to do. They are confused principals and once these principals are confused the rest of the school is also confused ... I really, really believe that current school principals should ... undergo some kind of professional development training.

The Aroha CHS principal stated:

... I believe that with professional development training for school principals, you would expect to see a lot of positive changes in our schools. There are lots of school principals currently serving in our community high school that really need this training ... If such professional development training is made available for our school principals I am sure that our community high school will improve greatly... Most school principals are underperforming in our schools because they do not know what they should be doing.... It is really urgent to ensure that our schools are performing effectively.

The findings highlight important elements associated with school planning and, in particular, the importance of planning as a mechanism to achieve the mission, vision and goals of a school. It has been suggested that school plans are seen as working documents that support the activities and development of the school. In this process, relationships are critically important. Prioritising professional development and ongoing support for school principals is a matter of urgent need.

\section{Conclusion}

While school planning is critical for schools, this research inquiry showed that most principals in community high schools do not have the full confidence to formulate, implement and successfully evaluate a school plan. Planning in schools can only become successful if current and future school principals undergo professional development that is geared towards improving their understanding and skills. Thorough 
understanding of the essential elements of the school planning process and ongoing support will greatly enhance current and future community high school principals' capacity to improve planning in schools.

Given the shortage of school leaders in the Solomon Islands, we wonder if some courses should become part of the pre-service teacher education programme. School planning might be taught alongside other planning aspects within a school, such as lesson planning modules, departmental planning or school development planning. This approach might assist teachers' confidence, making them more prepared to take on school leadership roles.

Having been a school leader in Solomon Islands, Sam experienced first-hand the need and pressure to develop a school plan. This experience frightened him and caused him to wonder, is this the experience of other school leaders in relation to school plans? We look forward to seeing professional development and support for existing and future school principals that better enables the school planning process.

\section{References}

Ahuru, S. (2010). School planning: An investigation into the factors that influence school planning in community high schools in the Solomon Islands from the principal's perspective (Unpublished master's thesis). University of Waikato, Hamilton, New Zealand.

Akao, S. M. (2008). Seen but not heard: Women's experiences of educational leadership in Solomon Islands secondary schools (Unpublished master's thesis). University of Waikato, Hamilton, New Zealand.

Aronson, J. (1994). A pragmatic view of thematic analysis. The Qualitative Report, 2(1). Retrieved from http://www.nova.edu/ssss/QR/BackIssues/QR21/aronson.html

Bouma, G. D. (1996). The research process (3rd ed.). Melbourne, Vic, Australia: Oxford University Press

Caldwell, B., \& Spinks, J. (1988). The self-managing school. London, England: Falmer Press.

Caldwell, B., \& Spinks, J. (1992). Leading the self-managing school. London, England: Falmer Press.

Davies, B., \& Anderson, L. (1992). Opting for self-management: The early experience of grant maintained schools. London, England: Routledge.

Davies, B., \& Ellison, L. (1997). School leadership for the 21st century: A competency and knowledge approach. London, England: Routledge.

Davies, B. \& Ellison, L. (1999). Strategic direction and development of the school. London, England: Routledge.

Davies, L. (1994). Beyond authoritarian school management: The challenge for transparency. Ticknall, England: Education Now Books.

Day, C., Harris, A., Hadfield, M., Tolley, H., \& Beresford, C. (2000). Leading schools in times of change. Buckingham, England: Open University Press.

Dimmock, C., \& Walker, A. (2002). Moving school leadership beyond its narrow boundaries: Developing cross-cultural approach. In K. Leithwood \& P. Hallinger (Eds.), Second international handbook of educational leadership and administration (pp. 267-204). Dordrecht, Netherlands: Kluwer. 
Donaldson, G. A., Jr. (2006). Cultivating leadership in schools: Connecting people, purpose and practice. New York, NY: Teachers College Press.

Duignan, P. (2006). Educational leadership: Key challenges and ethical tensions. New York, NY: Cambridge University Press.

Giles, D. L. (2008). Exploring the teacher-student relationship in teacher education: A hermeneutic phenomenological inquiry (Unpublished $\mathrm{PhD}$ thesis). Auckland University of Technology, Auckland, New Zealand.

Glover, D., \& Levacic, R. (2005). Financial material resources for learning. In M. Coleman \& P. Earley (Eds.), Leadership and management in education cultures, change and contexts (pp.167-186). Oxford, England: Oxford University Press.

Gunter, H. M. (2001). Leaders and leadership in education. London, England: Paul Chapman.

Hargreaves, D., \& Hopkins, D. (1991). The empowered school. London, England: Cassell.

Hargreaves, D., Hopkins, D., Leask, M., Connolly, J., \& Robinson, P. (1989). Planning for development. London, England: Department for Education and Science.

Helm, C. (2005). Why we need to plan and why we don't: Conquering the myths and mistakes of planning in uncertain times. Momentum, 36(3), 23-26.

Hodgkinson, C. (1991). Educational leadership: The moral art. New York: SUNY Press.

Hopkins, D. (2001). School improvement for real. London, England: RoutledgeFalmer.

Hopkins, D., Ainscow, M., \& West, E. (1994). School improvement in an era of change. London, England: Cassell.

Knoff, M. H. (2005). Building strong schools to strengthen student outcomes. Little Rock: Arkansas Department of Education.

Lipham, M. J., \& Hoeh, A. J. (1974). The principalship: Foundations and functions. New York, NY: Harper \& Row.

MacGilchrist, B., Mortimore, P., Savage, J., \& Beresford, C. (1997). The impact of development planning in primary schools. In M. Preedy, R. Glater, \& R. Levacic (Eds.), Educational management: Strategy quality, and resources (pp. 234-246). Buckingham, England: Open University Press.

Malasa, D. P. (2007). Effective school leadership: An exploration of the issues inhibiting the effectiveness of school leadership in Solomon Islands secondary schools (Unpublished master's thesis). University of Waikato, Hamilton, New Zealand.

Mutch, C. (2005). Doing educational research: A practitioner's guide to getting started. Wellington, New Zealand: NZCER Press.

Noonan, S. J. (2003). The elements of leadership: What you should know. Lanham, MD: Scarecrow Press.

Ramoni, J. M. (2000). Solomon Islands report of education for all (EFA). Honiara, Solomon Islands: Department of Education and Human Resources Development, Ministry of Education.

Solomon Islands Ministry of Education. (2004). Education strategic plan. Honiara, Solomon Islands: Government Press.

Stoll, L., \& Fink, D. (1996). Changing our schools: Linking school effectiveness and school improvement. Philadelphia, PA: Open University Press.

Waddel, D., Cummings, T, J., \& Worley, C. (2000). Organisation development and change. Nelson, New Zealand: Pacific Rim Edition. 
Samuel Aruhu has held a range of leadership roles in schools within the Solomon Islands. Influenced by these experiences, he recently completed his thesis, which focused on the experiences of school leaders in developing school plans, development plans, and operational plans. Samuel is keen to assist the professional learning of school leaders to this end. He is currently Principal of Pamua National Secondary School, Solomon Islands.

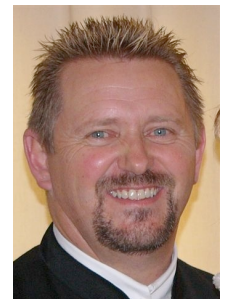

David Giles is an Associate Professor (Educational Leadership and Management) in the School of Education, Flinders University. He has extensive teaching and leadership experience in the primary, secondary and tertiary sectors. David has a particular interest in hermeneutic phenomenology and appreciative inquiry research methodologies as vehicles for exploring the experiential, relational \& phenomenological nature of educational leadership.

\footnotetext{
i Community high schools are high schools that have been established within local community. This type of high school has the particular characteristic that it is controlled by a local community and has the support of the Ministry of Education and Human Resource Development and other authorities.
} 
